\title{
Numerical Study of Effects of Different Base on Asphalt Pavement Responses Using FEM
}

\author{
Lu Bai ${ }^{1, a^{*}}$, Guo Cong ${ }^{2, b}$, Jianping Zhu ${ }^{3, \mathrm{c}}$ and Peng Li ${ }^{4, \mathrm{~d}}$ \\ ${ }^{1}$ Chang'an University, Middle section of er huan street, Xi'an, China \\ ${ }^{2}$ Chongqing Zhixiang Paving Technology Engineering CO.,LTD, \\ China Merchants Building,No.33 Xuefu Avenue, Nan'an Distract, Chongqing, China \\ ${ }^{3}$ China Merchants Chongqing Communications Research \& Design Institute CO.,LTD \\ China Merchants Building, No.33 Xuefu Avenue, Nan'an Distract, Chongqing \\ ${ }^{4}$ Chang'an University, Middle section of er huan street, Xi'an, China \\ a lubai1187@126.com, ${ }^{b}$ zhujianping@cmhk.com, ${ }^{c}$ zhujianping@cmhk.com, ${ }^{d}$ pengli_ak@qq.com
}

Keywords: asphalt pavement, FEM, pavement design, structural analysis

Abstract. The current trend of flexible pavement design is moving from an empirical approach to a mechanistic based design methodology. The equations used in the empirical design method to determine the pavement structure rely on the empirical relationships between design variables. These equations are only valid within the range, in which the data had been collected from test roads. The perceived deficiencies of the empirical design approach motivated engineers and researchers to develop the mechanistic-empirical methodology. The mechanistic analysis of flexible pavement is an essential part of mechanistic based design approach. The analysis provides pavement responses, such as stresses, strains and displacements, to traffic and environmental loading. Then, these responses are used in distress models to calculate damage accumulated over the design period. In this study, the commercial FEM package ABAQUS was used to analysis pavement response under wheel load. A typical pavement structure was selected. Four types of asphalt base material were used and the corresponding pavement responses under wheel load were analyzed and compared.

\section{Introduction}

The current trend of flexible pavement design is moving from an empirical approach to a mechanistic based design methodology. The equations used in the empirical design method to determine the pavement structure rely on the empirical relationships between design variables, such as axle load repetition, serviceability, layer thicknesses and layer coefficients, and there isn't a firm scientific basis for using these relationships. These equations are only valid within the range, in which the data had been collected from test roads. For example, the AASHTO guide (vision 1972-1993) was developed based on the data collected from the extensive AASHTO Road Test conducted in Ottawa, Illinois in the late 1950s and early 1960s. Once the design variables and requirements exceed the original conditions, the empirical approach cannot provide a confident estimate. The perceived deficiencies of the empirical design approach motivated engineers and researchers to develop the mechanistic-empirical methodology. The mechanistic analysis of flexible pavement is an essential part of mechanistic based design approach. The analysis provides pavement responses, such as stresses, strains and displacements, to traffic and environmental loading. Then, these responses are used in distress models to calculate damage accumulated over the design period.

Boussinesq [1] provided the solutions to calculate stress, strain and deformation for semi-infinite, homogeneous material under a concentrated load. By integrating the concentrated load over a circular area, the response due to a circular load can be obtained. Based on Boussinesq's theory, Foster and 
Ahlvin [2] developed charts for pavement design to determine horizontal stresses, vertical stresses, and elastic strains due to a circular load. However, the pavement structure can be better represented by a layered system than a semi-infinite, homogeneous space. Burmister [3] proposed a solution for a two-layer system based on linear elastic theory and later the solution was extended to a three-layer system [4]. The theory of elastic layered system is the basis of modern flexible pavement structure analysis. With the advent of the electronic computer, Burmister's solution has been extended to multilayer systems (Figure 1) through numerous computer programs. The solution of linear elastic-layered systems based on Burmister's theory requires numerical integration of an infinite series. Numerous computer programs have been developed based on this theory, such as CHEV5L [5], BISAR [6], VESYS [7], CIRCLY4 [8], VEROAD [9] and KENLAYER [10]. All of these programs provide similar responses to single and dual tire loading.

The primary limitation of using elastic-layered system is that it cannot consider complex material constitution model and complex geometry problem domain. The finite element method (FEM) can overcome these limitations and provides much more flexibility for pavement researchers and engineers.

In this study, the commercial FEM package ABAQUS was used to analysis pavement response under wheel load. A typical pavement structure was selected. Four types of asphalt base material were used and the corresponding pavement responses under wheel load were analyzed and compared.

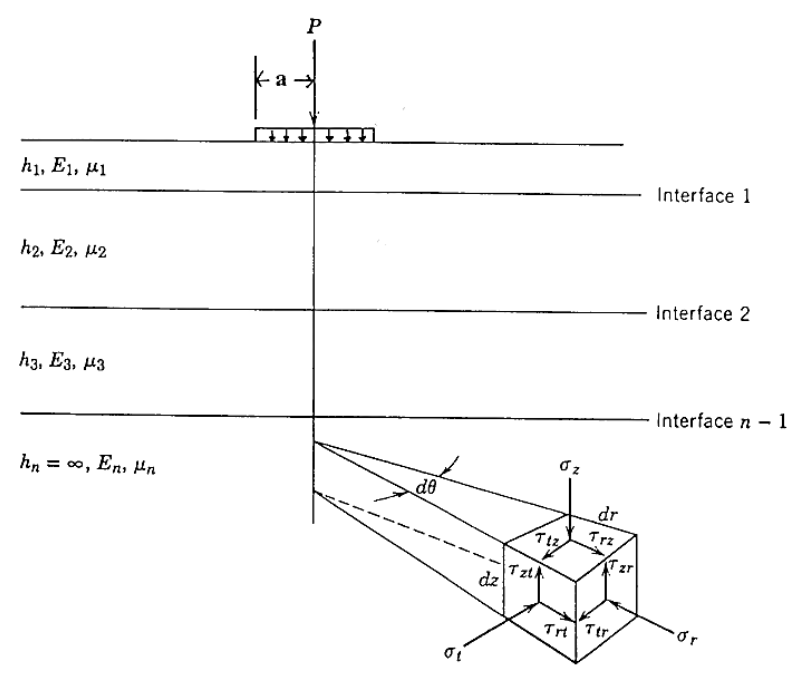

Figure 1 Generalized Multi-layer System

\section{FEM model configuration}

As illustrated in Figure 2, flexible pavement is treated as a multi-layered structure subjected to wheel loads. In this study, it was assumed that layers were fully bonded with each other. Generally in pavement design, the signal axle dual wheel loads are used as standard load. Each wheel load equals to $20 \mathrm{kN}$ (4500lb) and the space between centers of wheels is $0.343 \mathrm{~m}$ (13.5in.). The contact area between tire and pavement is simplified as a circular area with the radius of $0.1 \mathrm{~m}$ ( $4 \mathrm{in}$ ) and the pressure is evenly distributed on this area with the magnitudes of $620 \mathrm{kPa}(90 \mathrm{psi})$. Other types of wheel loads can be converted to this standard load. Both the two-dimension (2D) and the three-dimension (3D) FEM model had been used to simulate the pavement structure. In a 2D model, the pavement was treated as an axisymmetric structure and only single wheel load can be considered in such model. In this study, the 
3D pavement model was used to accurately simulate the pavement responses under the single axle dual wheels loading.

A typical pavement structure was chosen. The pavement structure consists of the surface layer, base course, subbase and subgrade. The thickness of each layer was determined based on the common practice. Table 1 summaries the layer thicknesses and materials properties of the FEM model built in this study.

Table 1 Materials Properties and Structure of FEM Pavement

\begin{tabular}{|c|c|c|c|c|c|c|}
\hline \hline \multirow{2}{*}{ Layer } & \multirow{2}{*}{ Material } & \multicolumn{2}{|c|}{ Thickness } & \multicolumn{2}{c|}{ Resilient Modulus } & Poisson's Ratio \\
\cline { 3 - 7 } & & $\mathrm{m}$ & in & $\mathrm{MPa}$ & $\mathrm{ksi}$ & \\
\hline \hline Surface & HMA & 0.05 & 2 & 3516 & 510 & 0.3 \\
\hline Base & ATB & 0.10 & 4 & 1724 & 250 & 0.35 \\
\hline Subbase & Selected_A & 0.61 & 24 & 275 & 40 & 0.4 \\
\hline Subgrade & Granular subgrade & $\infty$ & $\infty$ & 69 & 10 & 0.45 \\
\hline \hline
\end{tabular}

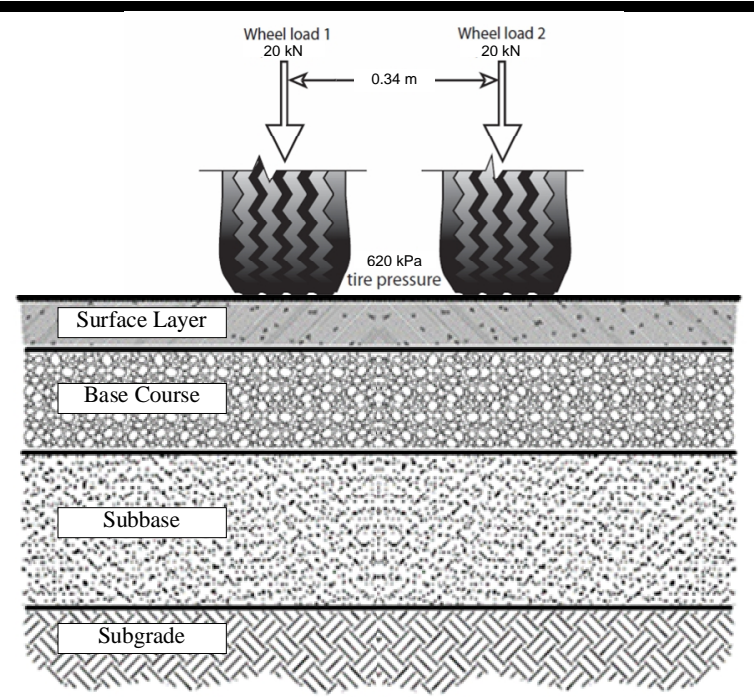

Figure 2 Loading Configuration

Since the pavement structure and loading condition are symmetric in both $\mathrm{x}$ and $\mathrm{y}$ directions (Figure 3), only a quarter of pavement structure was simulated in this study to conserve the computational power. Two types of elements were considered during the development of FEM pavement model, 8-node linear (first-order interpolation) brick and 20-node quadratic (second-order interpolation) brick. The quadratic element provides higher accuracy than the linear element. It is very effective in bending-dominated problems. However, the FEM model consisting of quadratic elements consumes more computational power than the one with linear elements. The mesh was automatically generated and its density was controlled by the number of seeds assigned on the edges.

Four types of asphalt bases material were selected in this study, and according to the asphalt binder content and environmental effects, there are 9 combinations for each type of asphalt base material. Totally, 36 pavement models were configured for FEM analysis. 


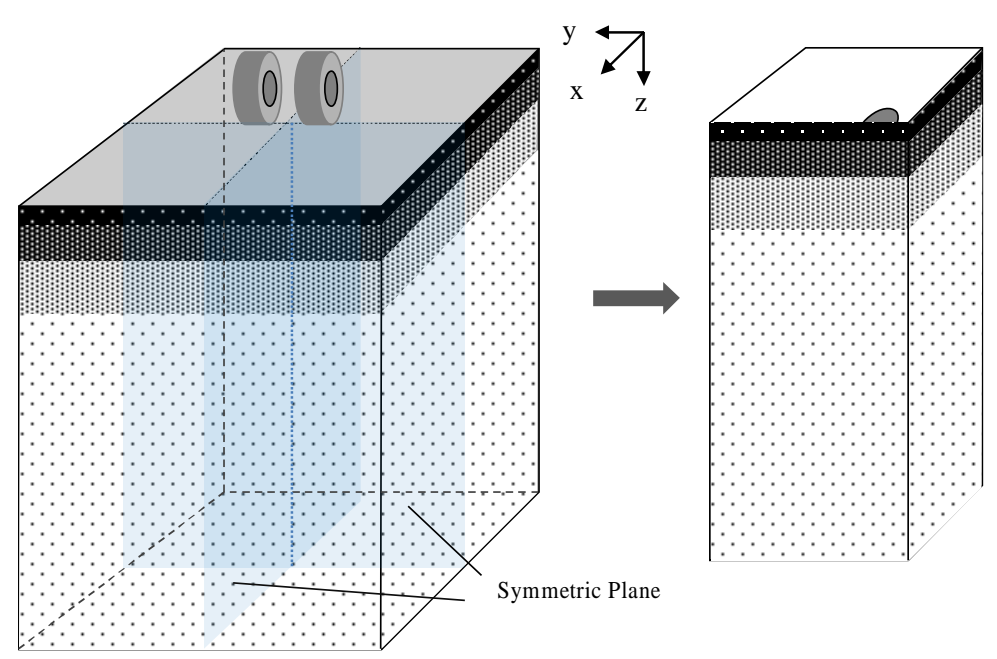

Figure 3 Pavement Model

\section{Simulation results}

The strain in the $\mathrm{x}$-direction $(\mathrm{x})$ and the maximum principal strain $\left(\begin{array}{l}1 \\ 1\end{array}\right)$ at the bottom of the base layer along the transverse path were collected from pavement analyses, because these two parameters are closely linked to the fatigue cracking of asphalt pavement. The data is presented in Figure 4 and 5, respectively. It clearly shows that the distribution of strain at the bottom of the base layer in the pavement using type 4 base material is different than the pavements using other base course materials. In the type 4 base, the maximum $\quad 1$ was observed at the outer side of the wheels and $\quad x$ was observed under the center of the wheel. Further analysis showed that the direction of 1 was along the transverse direction, which meant that if a crack could be formed and propagate through the layers, the direction of the crack would be along the roadway. However, it has been confirmed by field observations that the bottom up fatigue cracking is only formed in the transverse direction. Therefore, the tensile strain at the bottom of the type 4 base would not lead to cracks and it is not a critical pavement response. The bottom up fatigue cracking of pavement with type 4 base course material should be initiated at the bottom of HMA surface layer.

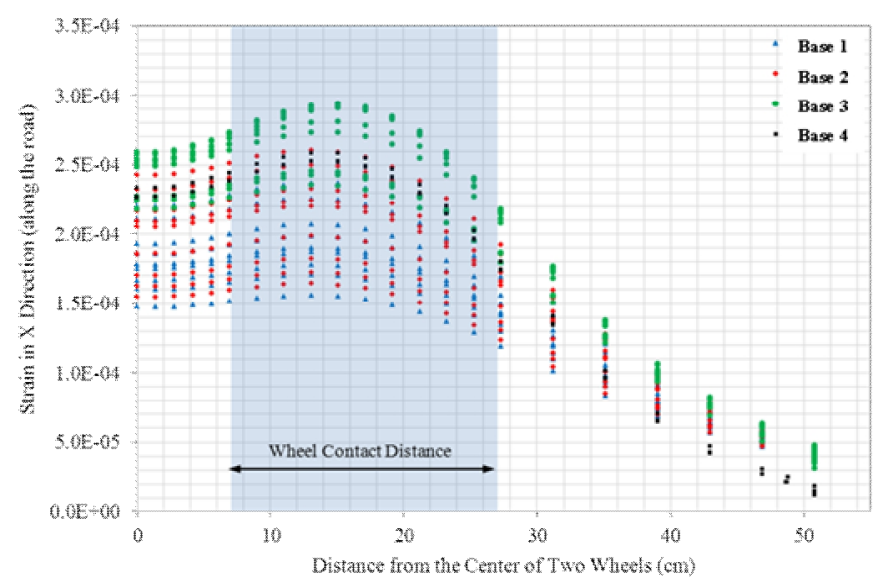

Figure $4{ }_{x}$ at the bottom of the Base along Transverse Path 
For the ${ }_{x}$, the maximum value always appears under the wheel contact area below the pavement surface and approximately in the center of the contact area, which means the critical location of ${ }_{x}$ is under the center of the wheel load.

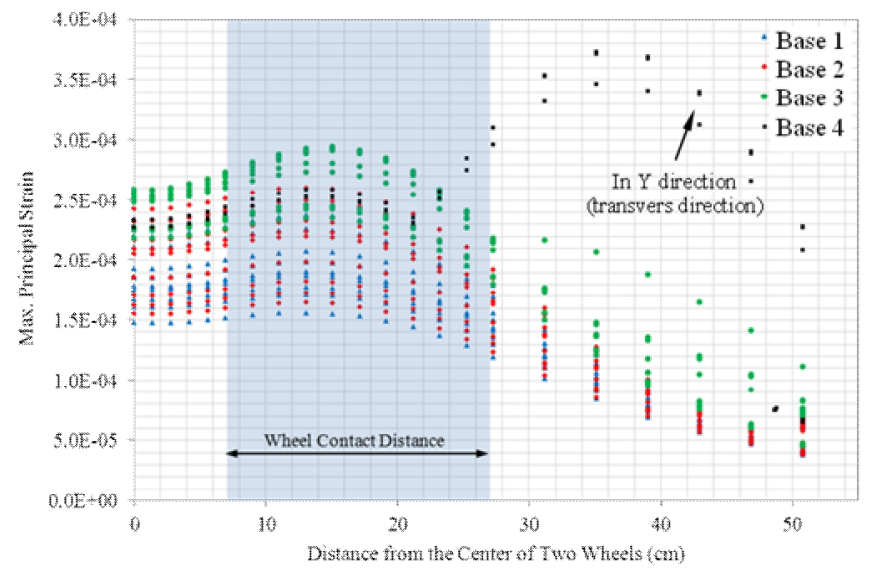

\section{Figure $5 \quad{ }_{1}$ at the bottom of the Base along Transverse Path}

The $\quad{ }_{v}$ at the top of the subbase along transverse path was also collected for comparison. The ${ }_{v}$ correlate to the permanent deformation of subgrade. The result is presented in Figure 6 . It can be seen that, among 4 types of materials, types 4 base leads the maximum vertical stress, which means the subgrade would have greater permanent deformation than pavements with other three types of base materials. The performance of type 1 base and type 2 base are very close.

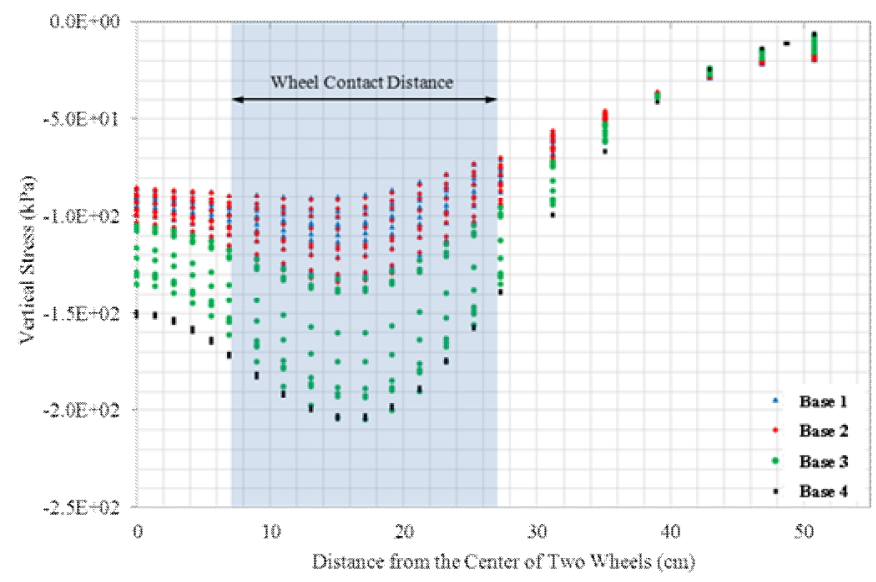

Figure 6 at the top of the Subbase along Transverse Path

\section{Conclusion}

In this study, four types of asphalt base material were used and the corresponding pavement responses under wheel load were analyzed using FEM software. It has been found that the ${ }_{x}$ and $\quad{ }_{v}$ are critical pavement responses and correlates to pavement fatigue cracking and subgrade permanent deformation, respectively. Among 4 types of base materials, types 4 base has the worst performance. The performance of base 1 and base 2 are similar.

\section{Reference}

[1] Boussinesq, J. (1885). Application des potentials a l'etude de l'equilibre et du Mouvement des Solids Elastiques, Gauthier-Villars, Paris, France 
[2] Foster, C. R., and Ahlvin, R. G. (1954) "Stresses and Deflections Induced by a Uniform Circluar Load." Highway Research Board, issue 33, 467-470.

[3] Burmister, D. M. (1943). "The Theory of Stresses and Displacements in Layered Systems and Applications to the Design of Airport Runways.” Highway Research Record, issue 23, 126-144.

[4] Burmister, D. M. (1945) The General Theory of Stresses and Displacements in layered Soil Systems, Journal of Applied Physics, 16(5), 296-302.

[5] Warren, H., and Dieckman, W. L. (1963). Numerical Computation of Stresses and Strains in a Multiple-Layer Asphalt Pavement System. International Report, Chevron Research Corporation, Richmond, CA

[6] De Jong, D.L., Peatz, M.G.F., and Korswagen, A.R. (1973) Computer Program Bisar Layered Systems under Normal and Tangential Loads. External Report AMSR.0006.73, Konin Klijke Shell-Laboratorium, Amsterdam.

[7] Moavenzadeh, F., Soussou, J.E., Findakly h.k., and Brademeyer, B. (1974) "Operating Instructions and program Documentation" Synthesis for Rational Design of Flexible Pavement, Part 3, Report, Federal Highway Administration, Washington, D.C

[8] Wardle, L.J., and B. Rodway. (1998) "Layered-Elastic Pavement Design - Recent Developments." Proc., Transport 1998, 19th ARRB Conference, Sydney, Australia.

[9] Nilsson, R.A (1999) Viscoelastic Approach to Flexible Pavement Design. PhD thesis, Dept. of Infrastructure and Planning, Royal Institute of Technology, Sweden.

[10] Huang, Y. H. (2004). Pavement analysis and design. 2nd Ed., Pearson Education, Inc., Upper Saddle River, NJ. 